\title{
Evolution of Stacking Faults in Substituted Nickel Hydroxide Spherical Powders
}

D.F. Wong ${ }^{1,2}$, K. Young ${ }^{1,2, *}$, L. Wang ${ }^{2}$, J. $\mathrm{Nei}^{2}$, K.Y.S. $\mathrm{Ng}^{1}$

${ }^{1}$ Department of Chemical Engineering and Materials Science, Wayne State University, MI 48202, USA

${ }^{2}$ BASF Battery Materials-Ovonic, 2983 Waterview Drive, Rochester Hills, MI 48309, USA

Abstract

Nickel hydroxide spherical powders contain small crystallite sizes and stacking faults that are necessary for electrochemical activity. Stacking faults along the $c$-axis orientation can be visualized by broadening and angular shifts in the $(h 0 l)$ diffraction peaks, which are directly correlated to the electrochemical utilization of these materials. Higher ratios of growth-type faults to deformation-type faults have been shown to correlate with metrics of high utilization, even after controlling for the total percentage of stacking faults. Depending on the additives, stacking faults tend to increase with precipitation time, but additives, such as $\mathrm{Zn}$, can affect the energy barriers so that precipitation conditions favor fewer stacking faults with precipitation time. Both Co and Zn suppress the percentage of stacking faults that occur in the materials, but a combination of $\mathrm{Co}$ and $\mathrm{Zn}$ allows the number of stacking faults to increase with precipitation time. The precipitation process has a significant role in the evolution of stacking faults, which can be further optimized to yield high electrochemical utilization in substituted nickel hydroxide spherical powders.

Keywords: Nickel hydroxide, X-ray diffraction, Stacking faults, Structural disorder, Computer simulation

\footnotetext{
* Corresponding author Tel: +1 248293 7000; fax: +1 248299 4520. E-mail address: kwo.young@basf.com (K. Young).
} 


\section{Introduction}

Pasted positive electrodes using nickel hydroxide spherical powders have improved sintered electrodes, increasing the loading and energy density for nickel-based batteries, including nickel-cadmium and nickel-metal hydride chemistries [1,2]. A maximum energy density of $400 \mathrm{mAh} \mathrm{cc}^{-1}$ is typical for sintered electrodes, while conventional powders have reported improvements up to $520 \mathrm{mAh} \mathrm{cc}^{-1}$ with the use of conductive additives [3]. Electrodes made from spherical powders typically reach an energy density of $>600 \mathrm{mAh} \mathrm{cc}^{-1}$, and the invention of a single-step, continuously-stirred reactor for producing various substituted nickel hydroxide spherical powders has enabled electrodes to reach $>700 \mathrm{mAh} \mathrm{cc}^{-1}$ [4]. Substituted nickel hydroxide spherical powders have been characterized by high tap densities $\left(>1.8 \mathrm{~g} \mathrm{cc}^{-1}\right)$ and small crystallite sizes (full-width at half-maximum (FWHM) $>0.8^{\circ}$ for the (101) diffraction peak), which are required for high electrochemical efficiency and energy density [5]. Highly crystalline $\beta$-nickel hydroxide has a predicted direct band gap of $E_{g}=2.90 \mathrm{eV}$ with UV spectroscopy measurements of $E_{g} \sim 3.0-3.5 \mathrm{eV}$ [6], showing that it is as a semi-conductor with behavior closer to insulators with poor conductivity and poor electrochemical activity. Substitutions, defects, and stacking faults within the crystal structure can facilitate the transport of the electrons and protons required for electrochemical reduction-oxidation reactions to occur. Powder X-ray diffraction (PXRD) patterns of the nickel hydroxide powders have given insight into the structural disorder of these materials. While the $(h k 0)$ and $(00 l)$ peaks are very sharp due to long-range periodicity, the (101) and (102) peak broadening observed in the PXRD patterns can be hypothesized to be related to the degree of stacking faults within the crystal structure $[7,8]$. 
The broadening of these specific peaks has been noted to correlate to electrochemical performance [9].

A method for simulating PXRD patterns in crystal structures that contain stacking faults has been developed by Treacy et al. and is implemented in a program called DIFFaX [10]. Several research groups have leveraged the DIFFaX program to study the stacking fault structure of nickel hydroxides and its effect on electrochemical properties. Delmas and Tessier were the first to correlate changes in the (101) and (102) peak widths through pattern matching of faulted structures generated by DIFFaX to two types of stacking faults: growth faults and deformation faults $[7,8]$. Ramesh and Kamath systematically analyzed the types of stacking faults with regard to their effects on PXRD patterns [11-13], and they have also investigated the effects of crystallinity and disorder on electrochemical performance [14-16]. Casas-Cabanas et al. compared anisotropic size effects to the stacking fault models and found that anisotropic crystallite sizes can also affect the peak broadening of the (101) and (102) peaks, but shifts in the peaks were solely correlated to stacking faults [17-20]. Stacking faults were found to be significant for smaller crystallite sizes (less than $350 \AA$ diameter and $100 \AA$ height), and the materials with the signature peak shifts showed higher electrochemical capacity.

Substituted nickel hydroxide spherical powders have small crystallite sizes and the highdensity of stacking faults that are necessary for electrochemical activity. Additives and precipitation conditions can greatly affect the morphology and defect structures of the powders, and the differences in the diffraction lines can be discerned from the PXRD patterns [21]. A better understanding of how stacking faults evolve with respect to preparation conditions can help researchers optimize the structures to promote high electrochemical activity. We have tracked substituted nickel hydroxide spherical powder samples at different precipitation times to 
study how stacking faults may change with time and composition via Rietveld refinement and DIFFaX simulation, and we present our findings in this paper.

\section{Experimental setup}

Substituted nickel hydroxide spherical powders were synthesized through the coprecipitation of metal sulfates $(\mathrm{Ni}, \mathrm{Co}$, and/or $\mathrm{Zn}$ ) with sodium hydroxide and ammonium hydroxide under strong stirring, at constant temperature, flow rate, and $\mathrm{pH}$, at a rate of $\sim 0.7 \mathrm{~kg}$ per day $[4,22]$. Product was collected as the overflow effluent from the top of the reactor. The precipitation process requires an initial "start-up" period, in which the particles in the precipitation process stabilize, and thereafter the product is considered to be "in spec". Samples were taken at different intervals during the precipitation, up to $32 \mathrm{~h}$, after which typical precipitation runs stabilize. Due to the small scale of the reactor, the samples were taken from the accumulation of a single collection container, which was mixed to ensure uniformity before sampling. The powder samples were washed and then dried overnight in an oven. A Rigaku Miniflex x-ray diffractometer was used to obtain PXRD patterns for pattern matching to DIFFaX simulation patterns.

\section{Structure refinement}

$\beta-\mathrm{Ni}(\mathrm{OH})_{2}$ has a hexagonal crystal structure belonging to space group P 3m1 with lattice parameters $a=3.13 \AA$ and $c=4.65 \AA$ [23]. Ni, O, and H occupy the $1 a, 2 d_{1}$, and $2 d_{2}$ sites, respectively, forming slabs composed of $\mathrm{H}, \mathrm{O}, \mathrm{Ni}, \mathrm{O}, \mathrm{H}$ layers. Structural disorder in the stacking of the slabs results in interstratification and stacking faults within the material, and the stacking faults fall under two major categories termed "deformation faults" and "growth faults" 
by Delmas and Tessier [7]. A detailed discussion of the different $\mathrm{Ni}(\mathrm{OH})_{2}$ polytypes and their stacking is discussed by Ramesh et al [12]. A first-principles study modeling the different stacking types found that deformation faults had the lowest energy of the stacking faults, indicating a higher probability for occurrences of the stacking fault [24]. Growth faults had the next lowest energy for a smaller probability of occurrences.

Structural disorder in the $\mathrm{Ni}(\mathrm{OH})_{2}$ crystal structure is constructed from repeating slabs stacked according to a defined stacking vector $(x, y, z)$. Ideal stacking along the $c$-axis has a stacking vector of $(0,0,1)$. The deformation fault has a stacking vector of $(1 / 3,2 / 3,1)$. The growth fault uses a slab with mirror symmetry to the original slab and has a stacking vector of $(1 / 3,2 / 3,1)$. Interstratification occurs when water is trapped between the slabs, and a stacking vector of $(x, y, 1.65)$ yields an interplanar spacing of $7.6 \AA$ to accommodate such water molecules [11]. The $x$ and $y$ are assigned random values in the simulation.

The Rietveld refinement technique was used to match the PXRD patterns generated by the DIFFaX program to the patterns obtained from the samples. We calculated $R^{2}$ and $R_{w p}$ factors to judge the quality of the refinement, and used the Nelder-Mead simplex algorithm to minimize $1-R^{2}$ and $R_{w p}$ values. Refinement parameters, such as the pseudo-Voigt instrument parameters $u$, $v, w, \sigma$, the lattice parameters $a, c$, the atomic positions, the stacking fault composition (ideal stacking, deformation faults, growth faults, and interstratification), the $z$-spacing for each type of fault, and the Debye temperature factors, were adjustable in the original DIFFaX program. However, we also implemented additional refinement parameters to account for the zero shift, scaling factor, $K_{\alpha 10,2}$ and background. We neglect the anisotropic crystallite size effects because at the small crystallite sizes, the peak shift signatures associated with stacking faults can be discerned and modeled. Due to the large number of refinement parameters, we designated a set 
of parameters to refine at a time, and iterated through the different sets numerous times until $R^{2}>$ $98 \%$ and $R_{w p}<5 \%$. For example, we first removed the diffraction peaks to fit the background parameters for the refinement, then fixed the background parameters to refine the lattice structure parameters, and so on. We were able to improve some poor refinements by using the refinement parameters from neighboring samples as initial input parameters.

\section{Results and discussion}

Eight compositions of the general formula $\mathrm{Ni}_{1-x-y} \mathrm{Co}_{x} \mathrm{Zn}_{y}(\mathrm{OH})_{2}$ were prepared, where $x$ and $y=0,0.03,0.06$, or 0.09 and $x+y \leq 0.09$. Each composition run was sampled nine times $(t$ $=1,2,3,4,6,8,24,28$, and $32 \mathrm{~h}$ ) during the precipitation process for a total of 72 different samples. Representative scanning electron microscopy images showing the spherical shape of the stabilized nickel hydroxide powder both unsubstituted $\left(\mathrm{Ni}(\mathrm{OH})_{2}\right)$ and substituted $\left(\mathrm{Ni}_{0.94} \mathrm{Co}_{0.03} \mathrm{Zn}_{0.03}(\mathrm{OH})_{2}\right)$ are provided in Figs. 1a and $1 \mathrm{~b}$, respectively. A list of the samples and some of their refined parameters are also provided in Table 1. A selection of the PXRD patterns for each composition sampled after $8 \mathrm{~h}$ and the patterns for the $\mathrm{Ni}(\mathrm{OH})_{2}$ composition sampled at each of the sampling times are shown in Figs. 2a and 2b. Representative pattern refinements of $\mathrm{Ni}(\mathrm{OH})_{2}$ after $32 \mathrm{~h}$ of precipitation and of $\mathrm{Ni}_{0.94} \mathrm{Co}_{0.03} \mathrm{Zn}_{0.03}(\mathrm{OH})_{2}$ after $8 \mathrm{~h}$ of precipitation are shown in Figs. 3a and 3b, respectively, to illustrate the goodness-of-fit. The $\mathrm{Ni}(\mathrm{OH})_{2}$ refinement is an example that demonstrates the typical fit of the refinement, while the $\mathrm{Ni}_{0.94} \mathrm{Co}_{0.03} \mathrm{Zn}_{0.03}(\mathrm{OH})_{2}$ refinement is an example showing a poorer fit. $\mathrm{Ni}_{0.94} \mathrm{Co}_{0.03} \mathrm{Zn}_{0.03}(\mathrm{OH})_{2}$ compositions show the most scatter in the refinement parameters due to the presence of a second peak near the (001) reflection. This second peak appears to be a second phase with a different $c$ lattice parameter because the intensity increase of the peak with precipitation time. However, 
segregation in terms of composition was not detected in electron dispersive spectroscopy (EDS) analysis. With the exception of some $\mathrm{Ni}_{0.94} \mathrm{Co}_{0.03} \mathrm{Zn}_{0.03}(\mathrm{OH})_{2}$ samples, refinement parameters appeared consistent, specifically falling within reasonable values and with small variation, due to aggregation of the powder samples over time.

\subsection{Effects of structural disorder on the (101) crystallite size}

The crystallite size estimated from the Scherrer equation, based on the FWHM of the (101) diffraction peak, correlates strongly with the utilization of the theoretical electrochemical capacity of $\beta-\mathrm{Ni}(\mathrm{OH})_{2}\left(289 \mathrm{mAh} \mathrm{g}^{-1}\right)$ [9]. The utilization increases as the (101) crystallite size decreases, and plateaus when the crystallite size falls below $\sim 100 \AA$. We use the (101) crystallite size as a metric to gauge the electrochemical utilization of the $\mathrm{Ni}(\mathrm{OH})_{2}$ samples, in lieu of electrochemical experiments. We plot the (101) crystallite size against the percentage of total structural disorder, as well as against the individual types of faults/disorder (deformation, growth, and interstratification), in Figs. 4a-4d, to visualize the contributions of the stacking faults against a metric for electrochemical utilization. The smallest crystallite sizes, which correlate with higher utilization, occur when total structural disorder is the largest, particularly for deformation and growth faults, but not for interstratification. The trends for deformation faults and growth faults largely follow the trend for total structural disorder, but deformation faults make up a larger proportion of the total disorder (maximum $\sim 14 \%$ deformation faults, $\sim 6 \%$ growth faults, $\sim 7 \%$ interstratification). The largest crystallite sizes occur when the structural disorder is low, but interstratification comprises the largest proportion of the disorder. Interstratification shows a large degree of scatter with respect to the (101) crystallite size. 


\subsection{Deformation faults vs. growth faults}

First principle calculations indicate that pure nickel hydroxide is expected to form deformation faults at a higher probability than growth faults [24]. Our refinements are consistent with this finding. Fig. 5 shows a plot of the percentage of growth faults with respect to the percentage of deformation faults, which further illustrates this correlation. Interestingly, there is also a wide band allowing a degree of variability that depends on precipitation time. To see the relative contributions of growth faults and deformation faults, we have plotted the (101) crystallite size metric with respect to the ratio of growth faults to deformation faults in Fig. 6 . For (101) crystallite sizes below $150 \AA$, there is a clear linear trend showing that a higher proportion of growth faults correlates to smaller crystallite sizes, which indicates a higher likelihood for higher electrochemical utilization. Ramesh et al. have also observed higher electrochemical utilization for samples that are modeled to have higher degrees of growth faults (called $2 \mathrm{H}_{2}$ faults in the paper) [25]. They highlight the observation that the structural differences in the $\left[\mathrm{HO}_{4}\right]$ tetrahedral provide instability to both types of faulted structures, which in turn facilitate the proton transfer needed for electrochemical activity. However, because there is a relationship between growth faults and deformation faults in terms of relative defect formation energies, we need to control for the total percentage of stacking faults to extricate the effects of growth faults from the effects originating with the total increase in stacking faults. Controlling for the total percentage of stacking faults shows that deformation faults have a stronger negative correlation to the (101) crystallite size when the number of growth faults is low. When growth faults are high, the growth faults have a stronger negative correlation than the deformation faults. This further supports the hypothesis that growth faults are a strong indicator for electrochemical utilization. Additional first-principles calculations that investigate how additives affect the 
stacking fault formation energies can be of interest, but it appears that the common Co and $\mathrm{Zn}$ additives do not lower the formation energies of growth faults below the energies of deformation faults.

\subsection{Evolution of stacking faults over precipitation time}

Precipitated nickel hydroxide powders prepared in a single-step, continuously-stirred reactor require time for the particles to reach a stabilized state, and there is a clear effect of the initial precipitation time on the distribution of the stacking faults. The strong stirring during the precipitation process appears to impart enough energy at the precipitation conditions (temperature and $\mathrm{pH}$ ) for the distribution of stacking faults to stabilize into a meta-stable state. The evolution of deformation faults over precipitation time is plotted in Figs. 7a-7c, and grouped by Co additives, $\mathrm{Zn}$ additives, and 0.06 level substitution, respectively. The evolution of growth faults over precipitation time is plotted in Figs. $8 \mathrm{a}-8 \mathrm{c}$. The refinements show very limited outliers, with the exception of $\mathrm{Ni}_{0.94} \mathrm{Co}_{0.03} \mathrm{Zn}_{0.03}(\mathrm{OH})_{2}$, which has been previously noted to show a second phase.

Generally, for the pure nickel hydroxide composition, there is little change in the percentage of deformation faults, and the increase in faulting arises from an increase in growth faults with precipitation time. Co additives appear to have a suppressive effect on both types of stacking faults, but a smaller suppressive effect is seen at higher levels of Co doping (Figs. $7 \mathrm{a}$ and 8a). Although the stacking faults levels are suppressed, in contrast to pure nickel hydroxide, the $\mathrm{Ni}_{0.91} \mathrm{Co}_{0.09}(\mathrm{OH})_{2}$ composition shows both deformation and growth faults increasing with precipitation time, corresponding to a decrease in the (101) crystallite size. Zn additives show a suppressive effect at all levels of substitution, with both types of stacking faults decreasing with 
precipitation time. It suggests that $\mathrm{Zn}$ is also able to modify the energy barriers so that the energy from the precipitation process overshoots the meta-stable states to fall to the stable, more highly crystalline state. The combination of $\mathrm{Co}$ and $\mathrm{Zn}$ additives at the 0.06 substitution level shows a small suppressive effect on the stacking faults, similar to Co. However, there is little change in the percentage of deformation faults with respect to precipitation time, but growth faults increase with longer precipitation times, contributing to the smaller (101) crystallite sizes seen over time. At the given experimental precipitation conditions, Co and $\mathrm{Zn}$ do not appear to promote the stacking faults needed for good electrochemical utilization; however, Co and $\mathrm{Zn}$ play other roles, providing needed conductivity and suppressing the formation of $\gamma-\mathrm{NiOOH}$ [5]. In addition, temperature and $\mathrm{pH}$ have an effect on the precipitation process, and further investigation into these conditions and how they affect the evolution of the stacking fault distribution for the various additives is an interesting direction for future research. We have shown through modeling of stacking faults how they may evolve with additives and precipitation time, which can be further optimized to yield better electrochemical utilization in substituted nickel hydroxide spherical powders.

\section{Conclusion}

Stacking faults in substituted nickel hydroxide spherical powders were studied using PXRD data and PXRD simulations modeled by the program DIFFaX. Higher proportions of growth faults compared to deformation faults are shown to be correlated to smaller (101) crystallite sizes, even after controlling for total percentage of stacking faults. Depending on the additives, stacking faults tend to increase with precipitation time, but additives, such as $\mathrm{Zn}$, can affect the energy barriers so that precipitation conditions favor less stacking faults with 
precipitation time. Both $\mathrm{Co}$ and $\mathrm{Zn}$ suppress the percentage of stacking faults that occur in nickel hydroxide spherical powders, but a combination of $\mathrm{Co}$ and $\mathrm{Zn}$ allows the stacking faults to increase with precipitation time.

\section{Acknowledgments}

This work is financially supported by ARPA-E under the robust affordable next generation EV-storage (RANGE) program (DE-AR0000386). We also acknowledge Dr.

Ramesh and Dr. Kamath for their help with insights into DIFFaX modeling.

\section{References}

[1] M. Oshitani, H. Yufu, U.S. Patent 4844999, 1989.

[2] M. Oshitani, K. Hasegawa, H. Yufu, U.S. Patent 4985318, 1991.

[3] M. Oshitani, H. Yufu, K. Takashima, S. Tsuji, Y. Matsumaru, J. Electrochem. Soc. 136 (1989) 1590-1593.

[4] C. Fierro, M.A. Fetcenko, K. Young, S.R. Ovshinsky, B. Sommers, C. Harrison, U.S. Patent 6228535, 2001.

[5] J. Chen, D.H. Bradhurst, S.X. Dou, H.K. Liu, J. Electrochem. Soc. 146 (1999) 36063612.

[6] P. Hermet, L. Gourrier, J.-L. Bantignies, D. Ravot, T. Michel, S. Deabate, P. Boulet, F. Henn, Physical Review B 84 (2011) 235211.

[7] C. Delmas, C. Tessier, J. Mater. Chem. 7 (1997) 1439-1443.

[8] C. Tessier, P.H. Haumesser, P. Bernard, C. Delmas, J. Electrochem. Soc. 146 (1999) 2059-2067.

[9] M. Terasaka, M. Kanbayashi, T. Shiojiri, Jpn. Patent H03-196588, 1993.

[10] M.M.J. Treacy, J.M. Newsam, M.W. Deem, Proc. R. Soc. A 433 (1991) 499-520.

[11] T.N. Ramesh, R.S. Jayashree, P.V. Kamath, Clays and Clay Minerals 51 (2003) 570-576. 
[12] T.N. Ramesh, P.V. Kamath, C. Shivakumara, Acta Crystallogr. Sect. B-Struct. Sci. 62 (2006) 530-536.

[13] T.N. Ramesh, P.V. Kamath, Mater. Res. Bull. 43 (2008) 3227-3233.

[14] T.N. Ramesh, Mater. Chem. Phys. 114 (2009) 618-623.

[15] T.N. Ramesh, P.V. Kamath, J. Solid State Electrochem. 13 (2009) 763-771.

[16] T.N. Ramesh, Indian Journal of Materials Science 2015 (2015) 7.

[17] M. Casas-Cabanas, M.R. Palacin, J. Rodriguez-Carvajal, Powder Diffraction 20 (2005) 334-344.

[18] M. Casas-Cabanas, J. Rodriguez-Carvajal, M.R. Palacin, Z. Kristallogr. (2006) 243-248.

[19] M. Casas-Cabanas, J. Rodriguez-Carvajal, J. Canales-Vazquez, M.R. Palacin, J. Mater. Chem. 16 (2006) 2925-2939.

[20] M. Casas-Cabanas, J. Rodriguez-Carvajal, J. Canales-Vazquez, Y. Laligant, P. Lacorre, M.R. Palacin, J. Power Sources 174 (2007) 414-420.

[21] D.S. Hall, D.J. Lockwood, C. Bock, B.R. MacDougall, Proceedings of the Royal Society of London A: Mathematical, Physical and Engineering Sciences 471 (2015).

[22] C. Fierro, A. Zallen, J. Koch, M. Fetcenko, J. Electrochem. Soc. 153 (2006) A492-A496.

[23] A. Szytula, A. Murasik, M. Balanda, Phys. Status Solidi B 43 (1971) 125-128.

[24] M.N. Tripathi, U.V. Waghmare, T.N. Ramesh, P.V. Kamath, J. Electrochem. Soc. 157 (2010) A280-A284.

[25] T.N. Ramesh, P.V. Kamath, Mater. Res. Bull. 43 (2008) 2827-2832.

\section{Figure Caption:}

Fig. 1

Representative scanning electron microscopy images showing the spherical size and shape of the stabilized nickel hydroxide powders produced by a single-step, continuously-stirred reactor for (a) $\mathrm{Ni}(\mathrm{OH})_{2}$ and (b) $\mathrm{Ni}_{0.94} \mathrm{Co}_{0.03} \mathrm{Zn}_{0.03}(\mathrm{OH})_{2}$. 
Fig. 2

Experimental PXRD patterns for (a) $\mathrm{Ni}(\mathrm{OH})_{2}$ sampled up to $32 \mathrm{~h}$ of precipitation time and (b) all compositions sampled at $8 \mathrm{~h}$ of precipitation time.

Fig. 3

Experimental PXRD patterns, fitted backgrounds, calculated patterns and refinement differences for (a) $\mathrm{Ni}(\mathrm{OH})_{2}$ sampled at $32 \mathrm{~h}$ of precipitation time and (b) $\mathrm{Ni}_{0.94} \mathrm{Co}_{0.03} \mathrm{Zn}_{0.03}(\mathrm{OH})_{2}$ sampled at $8 \mathrm{~h}$ of precipitation time.

Fig. 4

Plots of the crystallite size calculated from the Scherrer equation using the full-width at halfmaximum of the (101) diffraction peak, which is also a metric of electrochemical utilization in nickel hydroxide materials, as functions of (a) total structural disorder, (b) deformation faults, (c) growth faults, and (d) interstratification.

Fig. 5

Plot of growth faults as a function of deformation faults, grouped by the composition of the substituted nickel hydroxide powders.

Fig. 6

Plot of (101) crystallite size as a function of the ratio of growth-to-deformation faults.

Fig. 7

Plots of deformation faults as a function of precipitation time for (a) various levels of Co additive, (b) various levels of $\mathrm{Zn}$ additive, and (c) Co and/or $\mathrm{Zn}$ additives at the 0.06 substitution level. 
Fig. 8

Plots of growth faults as a function of precipitation time for (a) various levels of Co additive, (b) various levels of $\mathrm{Zn}$ additive, and (c) Co and/or $\mathrm{Zn}$ additives at the 0.06 substitution level. 
Table 1 Summary of select structural parameters and refinements for substituted nickel hydroxide spherical powders. Crystallite sizes (XS) are estimated using the Scherrer equation.

\begin{tabular}{|c|c|c|c|c|c|c|c|c|c|c|}
\hline Composition & $\begin{array}{l}\text { Time } \\
\text { (h) }\end{array}$ & $\begin{array}{l}a \\
(\AA)\end{array}$ & $\begin{array}{l}c \\
(\AA)\end{array}$ & $\begin{array}{l}\text { Ideal } \\
\text { Stacking }\end{array}$ & $\begin{array}{l}\text { Deform. } \\
\text { Faults }\end{array}$ & $\begin{array}{l}\text { Growth } \\
\text { Faults }\end{array}$ & $\begin{array}{l}\text { Interstrat- } \\
\text { ification }\end{array}$ & $\begin{array}{l}\mathrm{XS}_{(100)} \\
(\AA)\end{array}$ & $\begin{array}{l}\mathrm{XS}_{(001)} \\
(\AA)\end{array}$ & $\begin{array}{l}\mathrm{XS}_{(101)} \\
(\AA)\end{array}$ \\
\hline \multirow[t]{9}{*}{$\mathrm{Ni}(\mathrm{OH})_{2}$} & 1 & 3.122 & 4.645 & 0.781 & 0.140 & 0.044 & 0.035 & 218.3 & 112.0 & 89.6 \\
\hline & 2 & 3.122 & 4.644 & 0.784 & 0.141 & 0.040 & 0.035 & 218.3 & 112.0 & 91.5 \\
\hline & 3 & 3.122 & 4.648 & 0.792 & 0.130 & 0.043 & 0.035 & 218.3 & 108.9 & 91.5 \\
\hline & 4 & 3.122 & 4.650 & 0.781 & 0.139 & 0.044 & 0.036 & 218.3 & 112.0 & 89.6 \\
\hline & 6 & 3.122 & 4.649 & 0.783 & 0.140 & 0.040 & 0.037 & 218.3 & 109.0 & 87.7 \\
\hline & 8 & 3.122 & 4.650 & 0.790 & 0.128 & 0.047 & 0.035 & 218.3 & 108.9 & 85.9 \\
\hline & 24 & 3.122 & 4.655 & 0.784 & 0.132 & 0.053 & 0.030 & 207.4 & 106.1 & 81.0 \\
\hline & 28 & 3.123 & 4.655 & 0.789 & 0.126 & 0.057 & 0.027 & 207.4 & 103.4 & 78.0 \\
\hline & 32 & 3.122 & 4.654 & 0.779 & 0.138 & 0.058 & 0.026 & 207.4 & 103.4 & 76.6 \\
\hline \multirow[t]{9}{*}{$\mathrm{Ni}_{0.97} \mathrm{Co}_{0.03}(\mathrm{OH})_{2}$} & 1 & 3.124 & 4.651 & 0.902 & 0.049 & 0.002 & 0.047 & 244.0 & 118.6 & 145.2 \\
\hline & 2 & 3.124 & 4.649 & 0.907 & 0.045 & 0.000 & 0.048 & 259.2 & 115.2 & 150.4 \\
\hline & 3 & 3.126 & 4.652 & 0.906 & 0.048 & 0.000 & 0.046 & 244.0 & 118.6 & 145.2 \\
\hline & 4 & 3.124 & 4.649 & 0.906 & 0.047 & 0.000 & 0.047 & 244.0 & 115.2 & 145.2 \\
\hline & 6 & 3.124 & 4.650 & 0.906 & 0.046 & 0.000 & 0.048 & 259.2 & 115.2 & 145.2 \\
\hline & 8 & 3.124 & 4.651 & 0.904 & 0.046 & 0.000 & 0.049 & 244.0 & 115.2 & 145.2 \\
\hline & 24 & 3.122 & 4.656 & 0.892 & 0.054 & 0.001 & 0.053 & 244.0 & 109.0 & 140.4 \\
\hline & 28 & 3.123 & 4.656 & 0.892 & 0.052 & 0.004 & 0.052 & 244.0 & 109.0 & 140.4 \\
\hline & 32 & 3.124 & 4.658 & 0.893 & 0.053 & 0.003 & 0.051 & 244.0 & 112.0 & 145.2 \\
\hline \multirow[t]{9}{*}{$\mathrm{Ni}_{0.94} \mathrm{Co}_{0.06}(\mathrm{OH})_{2}$} & 1 & 3.122 & 4.657 & 0.880 & 0.059 & 0.003 & 0.058 & 244.0 & 100.8 & 135.8 \\
\hline & 2 & 3.122 & 4.657 & 0.883 & 0.059 & 0.000 & 0.058 & 243.9 & 100.8 & 135.8 \\
\hline & 3 & 3.122 & 4.658 & 0.883 & 0.058 & 0.001 & 0.057 & 244.0 & 103.4 & 135.9 \\
\hline & 4 & 3.122 & 4.657 & 0.885 & 0.057 & 0.001 & 0.057 & 243.9 & 103.4 & 135.8 \\
\hline & 6 & 3.122 & 4.657 & 0.884 & 0.057 & 0.002 & 0.057 & 244.0 & 103.4 & 135.8 \\
\hline & 8 & 3.122 & 4.657 & 0.883 & 0.058 & 0.002 & 0.057 & 243.9 & 106.1 & 140.4 \\
\hline & 24 & 3.122 & 4.657 & 0.884 & 0.058 & 0.001 & 0.057 & 244.0 & 103.4 & 135.8 \\
\hline & 28 & 3.122 & 4.658 & 0.883 & 0.057 & 0.001 & 0.059 & 244.0 & 106.1 & 145.2 \\
\hline & 32 & 3.122 & 4.657 & 0.883 & 0.056 & 0.002 & 0.059 & 244.0 & 106.1 & 145.2 \\
\hline $\mathrm{Ni}_{0.91} \mathrm{Co}_{0.09}(\mathrm{OH})_{2}$ & 1 & 3.126 & 4.647 & 0.888 & 0.056 & 0.002 & 0.053 & 243.9 & 139.0 & 145.2 \\
\hline
\end{tabular}




\begin{tabular}{|c|c|c|c|c|c|c|c|c|c|c|}
\hline & 2 & 3.126 & 4.645 & 0.886 & 0.060 & 0.002 & 0.052 & 243.9 & 139.0 & 145.2 \\
\hline & 3 & 3.126 & 4.650 & 0.880 & 0.058 & 0.003 & 0.058 & 230.4 & 134.4 & 145.2 \\
\hline & 4 & 3.126 & 4.648 & 0.887 & 0.057 & 0.002 & 0.055 & 230.4 & 139.0 & 145.2 \\
\hline & 6 & 3.126 & 4.651 & 0.867 & 0.064 & 0.005 & 0.064 & 243.9 & 134.4 & 140.4 \\
\hline & 8 & 3.126 & 4.648 & 0.892 & 0.053 & 0.005 & 0.050 & 243.9 & 139.0 & 145.2 \\
\hline & 24 & 3.126 & 4.638 & 0.849 & 0.092 & 0.020 & 0.040 & 218.3 & 98.3 & 105.3 \\
\hline & 28 & 3.126 & 4.639 & 0.850 & 0.086 & 0.021 & 0.044 & 244.0 & 93.8 & 108.0 \\
\hline & 32 & 3.126 & 4.636 & 0.859 & 0.079 & 0.022 & 0.040 & 230.4 & 93.8 & 117.0 \\
\hline \multirow[t]{9}{*}{$\mathrm{Ni}_{0.97} \mathrm{Zn}_{0.03}(\mathrm{OH})_{2}$} & 1 & 3.128 & 4.648 & 0.857 & 0.069 & 0.021 & 0.053 & 243.9 & 118.6 & 117.0 \\
\hline & 2 & 3.128 & 4.648 & 0.855 & 0.073 & 0.011 & 0.061 & 243.9 & 115.2 & 120.3 \\
\hline & 3 & 3.128 & 4.647 & 0.856 & 0.072 & 0.014 & 0.058 & 243.9 & 118.6 & 127.6 \\
\hline & 4 & 3.129 & 4.646 & 0.859 & 0.066 & 0.018 & 0.056 & 230.4 & 122.2 & 123.9 \\
\hline & 6 & 3.129 & 4.646 & 0.869 & 0.063 & 0.013 & 0.055 & 243.9 & 126.0 & 127.6 \\
\hline & 8 & 3.130 & 4.646 & 0.875 & 0.059 & 0.008 & 0.058 & 243.9 & 126.0 & 131.6 \\
\hline & 24 & 3.130 & 4.644 & 0.897 & 0.051 & 0.002 & 0.051 & 259.2 & 144.0 & 145.2 \\
\hline & 28 & 3.130 & 4.644 & 0.896 & 0.052 & 0.001 & 0.051 & 244.0 & 139.0 & 145.3 \\
\hline & 32 & 3.129 & 4.644 & 0.893 & 0.052 & 0.001 & 0.053 & 244.0 & 144.0 & 150.4 \\
\hline \multirow[t]{9}{*}{$\mathrm{Ni}_{0.94} \mathrm{Zn}_{0.06}(\mathrm{OH})_{2}$} & 1 & 3.124 & 4.648 & 0.857 & 0.077 & 0.005 & 0.061 & 230.4 & 118.6 & 131.6 \\
\hline & 2 & 3.124 & 4.646 & 0.855 & 0.080 & 0.007 & 0.058 & 244.0 & 122.2 & 127.6 \\
\hline & 3 & 3.124 & 4.644 & 0.868 & 0.073 & 0.005 & 0.053 & 244.0 & 122.2 & 131.6 \\
\hline & 4 & 3.122 & 4.645 & 0.861 & 0.075 & 0.008 & 0.056 & 244.0 & 122.2 & 131.6 \\
\hline & 6 & 3.124 & 4.639 & 0.867 & 0.083 & 0.015 & 0.035 & 244.0 & 126.0 & 127.6 \\
\hline & 8 & 3.124 & 4.636 & 0.872 & 0.085 & 0.014 & 0.029 & 244.0 & 130.1 & 135.8 \\
\hline & 24 & 3.124 & 4.639 & 0.897 & 0.057 & 0.004 & 0.042 & 244.0 & 134.4 & 140.4 \\
\hline & 28 & 3.124 & 4.638 & 0.899 & 0.056 & 0.003 & 0.041 & 244.0 & 134.4 & 140.4 \\
\hline & 32 & 3.124 & 4.636 & 0.900 & 0.060 & 0.003 & 0.037 & 243.9 & 134.4 & 145.2 \\
\hline \multirow{7}{*}{$\mathrm{Ni}_{0.91} \mathrm{Zn}_{0.09}(\mathrm{OH})_{2}$} & 1 & 3.132 & 4.654 & 0.911 & 0.029 & 0.000 & 0.060 & 276.4 & 144.0 & 183.1 \\
\hline & 2 & 3.130 & 4.655 & 0.898 & 0.031 & 0.002 & 0.069 & 259.2 & 144.0 & 175.5 \\
\hline & 3 & 3.132 & 4.655 & 0.906 & 0.030 & 0.000 & 0.064 & 259.2 & 139.0 & 183.1 \\
\hline & 4 & 3.132 & 4.657 & 0.899 & 0.032 & 0.001 & 0.067 & 276.5 & 134.4 & 175.5 \\
\hline & 6 & 3.134 & 4.660 & 0.902 & 0.027 & 0.001 & 0.070 & 259.4 & 139.1 & 175.6 \\
\hline & 8 & 3.134 & 4.656 & 0.911 & 0.028 & 0.000 & 0.061 & 276.6 & 144.0 & 183.2 \\
\hline & 24 & 3.133 & 4.653 & 0.913 & 0.024 & 0.001 & 0.063 & 276.5 & 155.1 & 200.5 \\
\hline
\end{tabular}




\begin{tabular}{lrrrrrrrrrr} 
& 28 & 3.132 & 4.654 & 0.909 & 0.025 & 0.000 & 0.066 & 276.4 & 155.1 & 200.5 \\
$\mathrm{Ni}_{0.94} \mathrm{Co}_{0.03} \mathrm{Zn}_{0.03}(\mathrm{OH})_{2}$ & 32 & 3.132 & 4.653 & 0.912 & 0.025 & 0.000 & 0.063 & 276.4 & 155.1 & 191.4 \\
& 1 & 3.126 & 4.674 & 0.848 & 0.075 & 0.005 & 0.072 & 243.9 & 87.6 & 123.8 \\
& 2 & 3.126 & 4.676 & 0.845 & 0.078 & 0.004 & 0.073 & 244.0 & 80.6 & 123.9 \\
& 3 & 3.126 & 4.674 & 0.850 & 0.074 & 0.005 & 0.071 & 259.2 & 85.8 & 123.8 \\
& 4 & 3.126 & 4.672 & 0.851 & 0.075 & 0.006 & 0.068 & 259.2 & 85.8 & 123.9 \\
& 6 & 3.126 & 4.663 & 0.858 & 0.076 & 0.025 & 0.041 & 243.9 & 73.3 & 117.0 \\
& 8 & 3.126 & 4.677 & 0.845 & 0.079 & 0.006 & 0.071 & 244.0 & 84.0 & 120.3 \\
& 24 & 3.124 & 4.673 & 0.853 & 0.077 & 0.020 & 0.049 & 244.0 & 87.6 & 117.0 \\
& 28 & 3.124 & 4.668 & 0.846 & 0.086 & 0.028 & 0.040 & 244.0 & 68.3 & 105.3 \\
& 32 & 3.124 & 4.668 & 0.861 & 0.077 & 0.028 & 0.035 & 244.0 & 87.6 & 117.0 \\
\hline
\end{tabular}




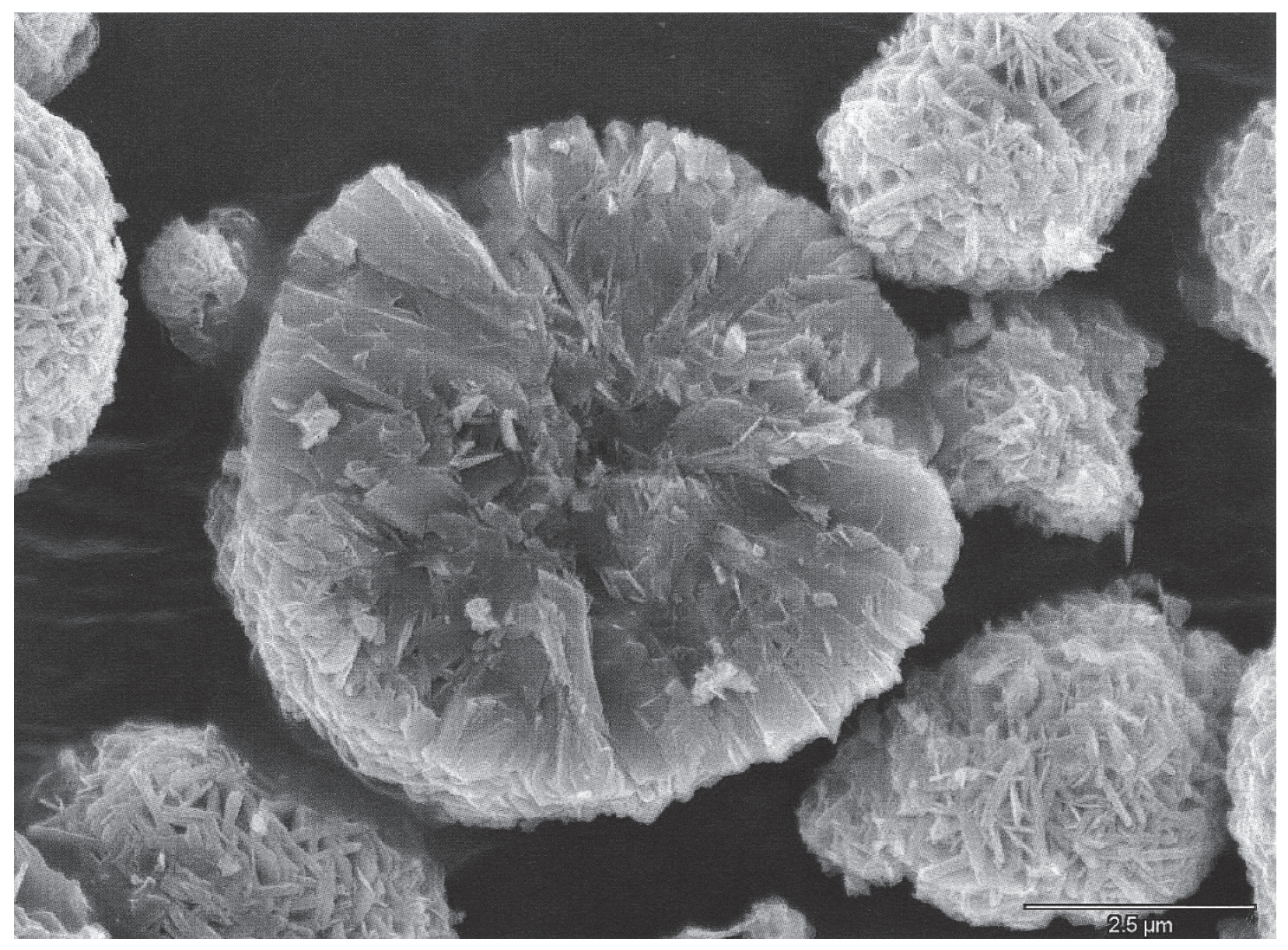

\section{Fig. 1a}




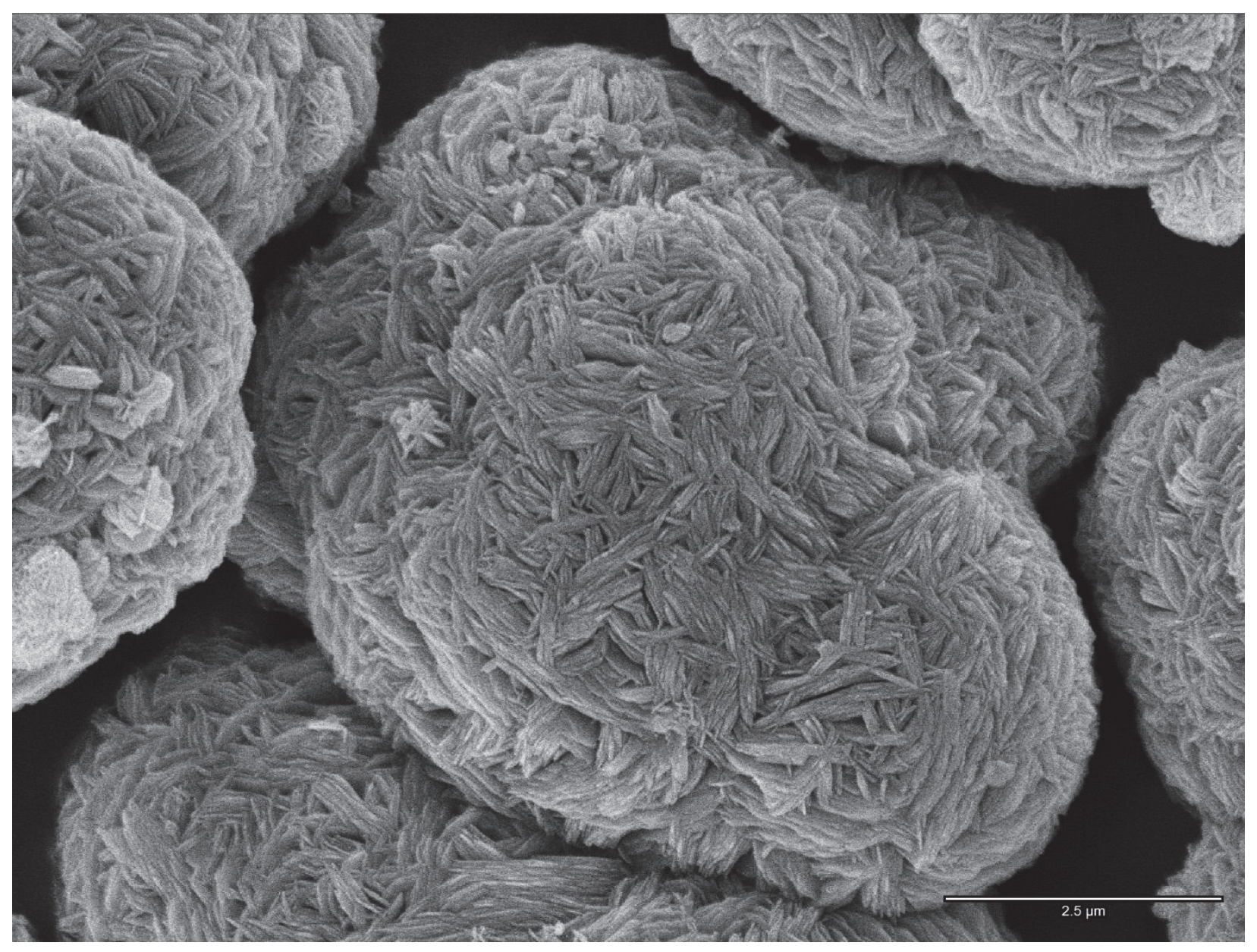

\section{Fig. 1b}




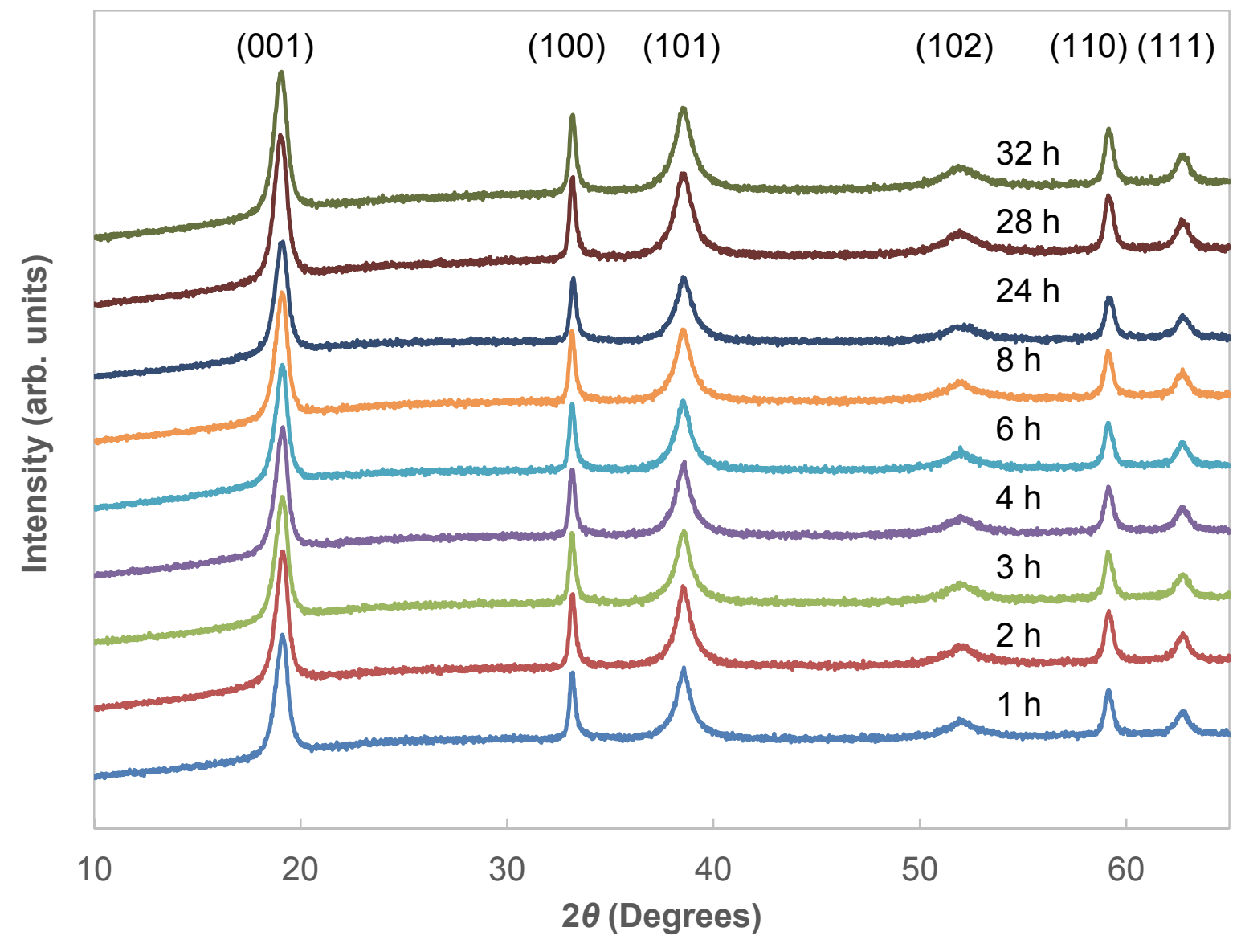

Fig. 2a 


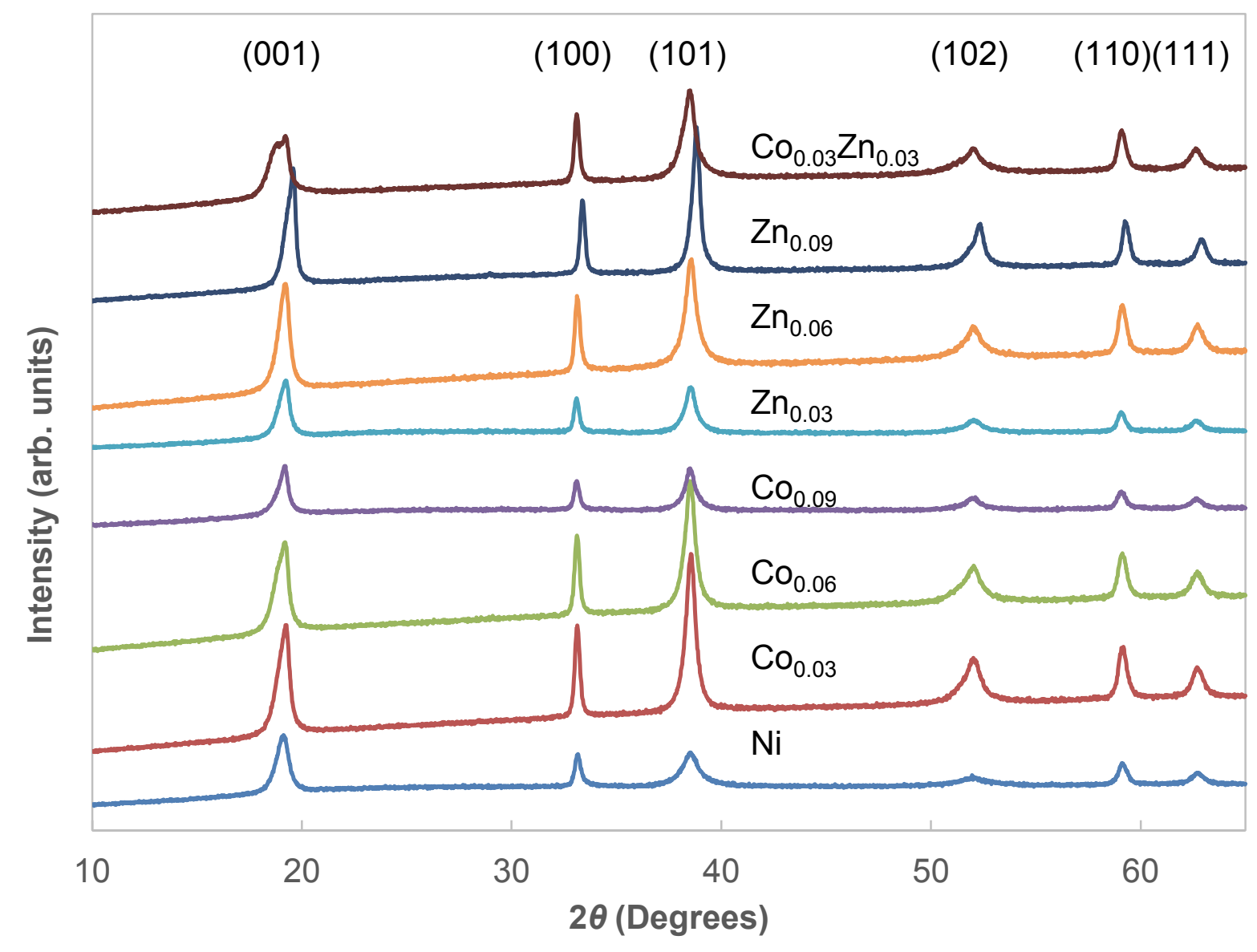

Fig. $2 b$ 


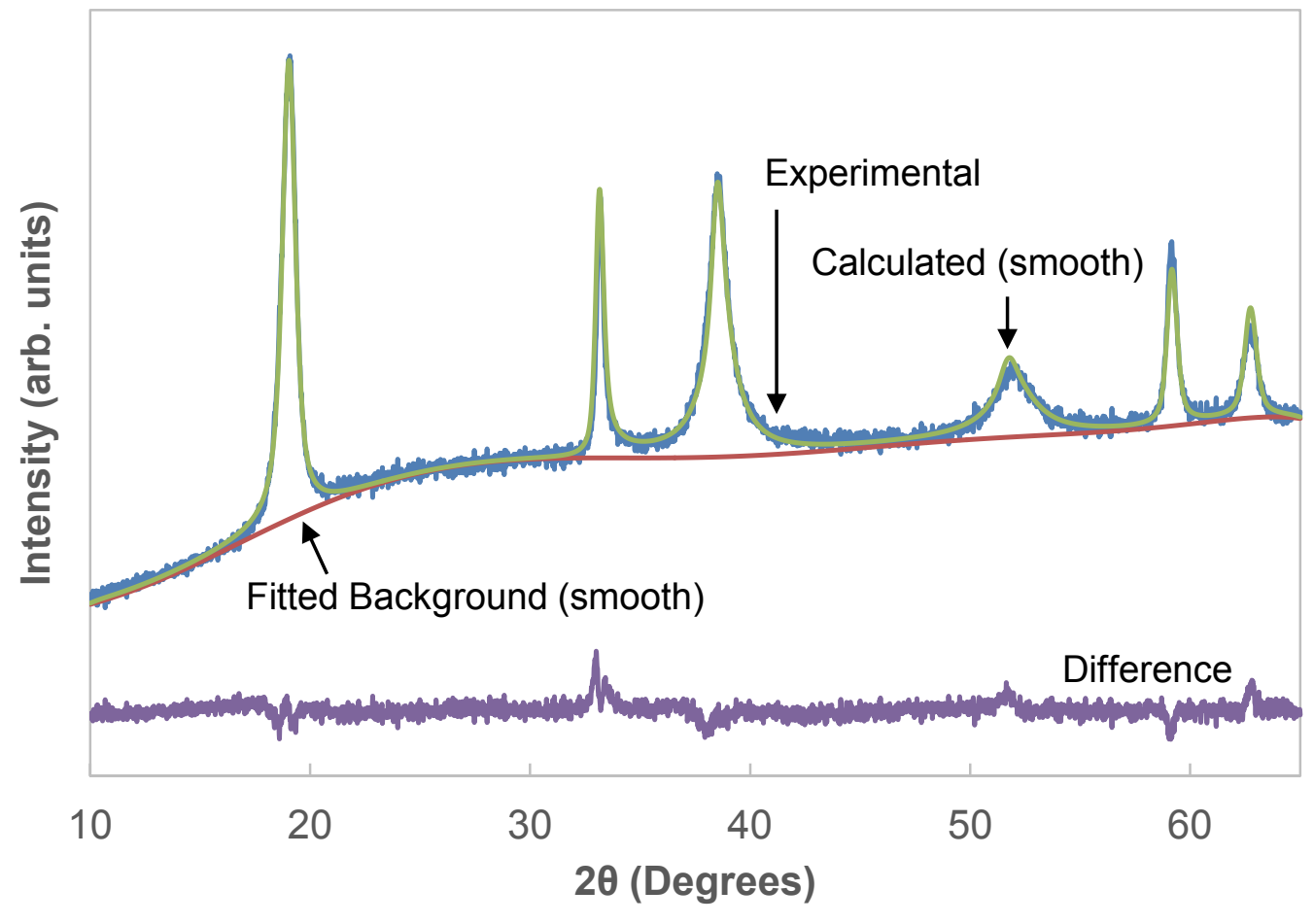

Fig. 3a 


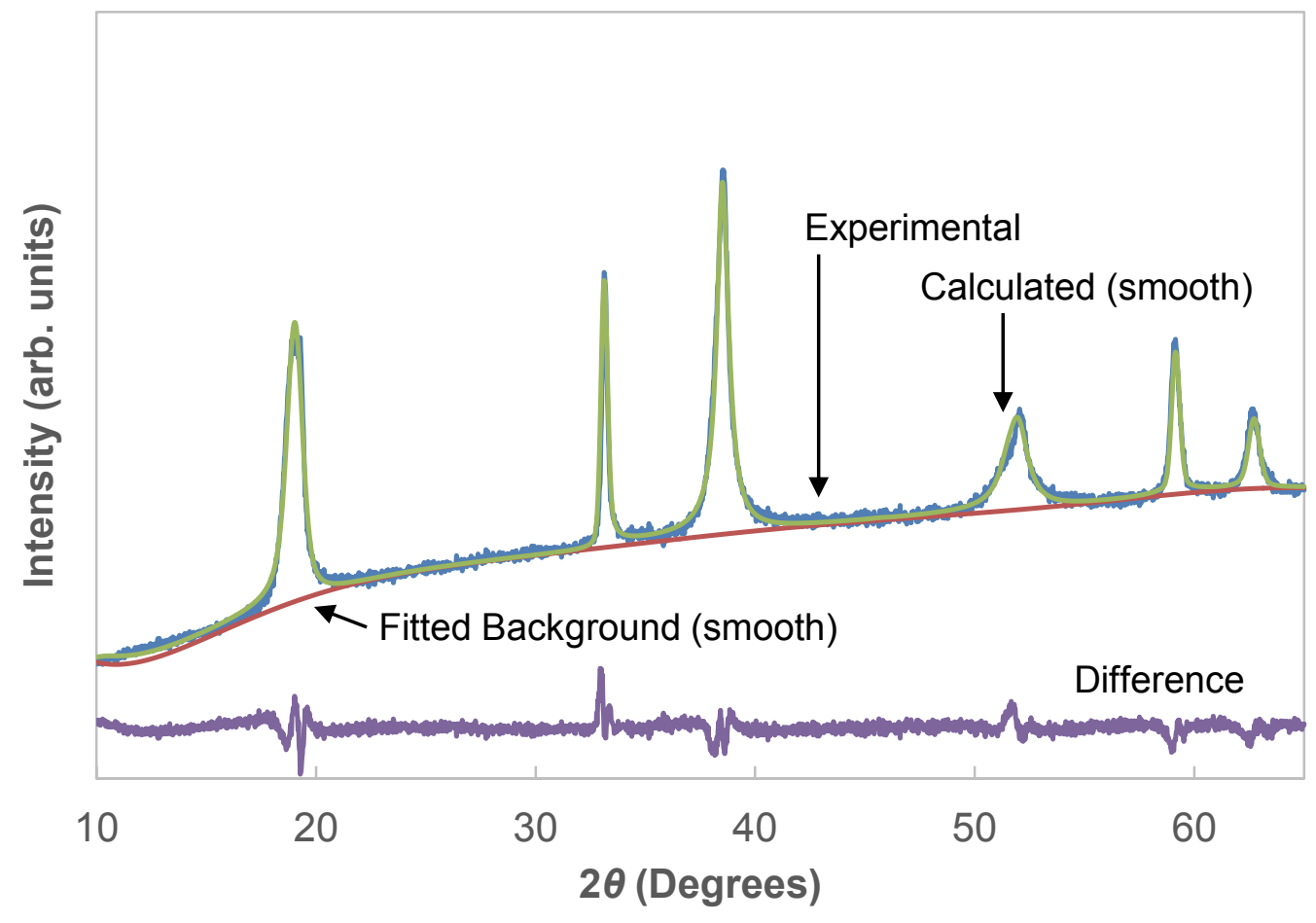

Fig. 3b 


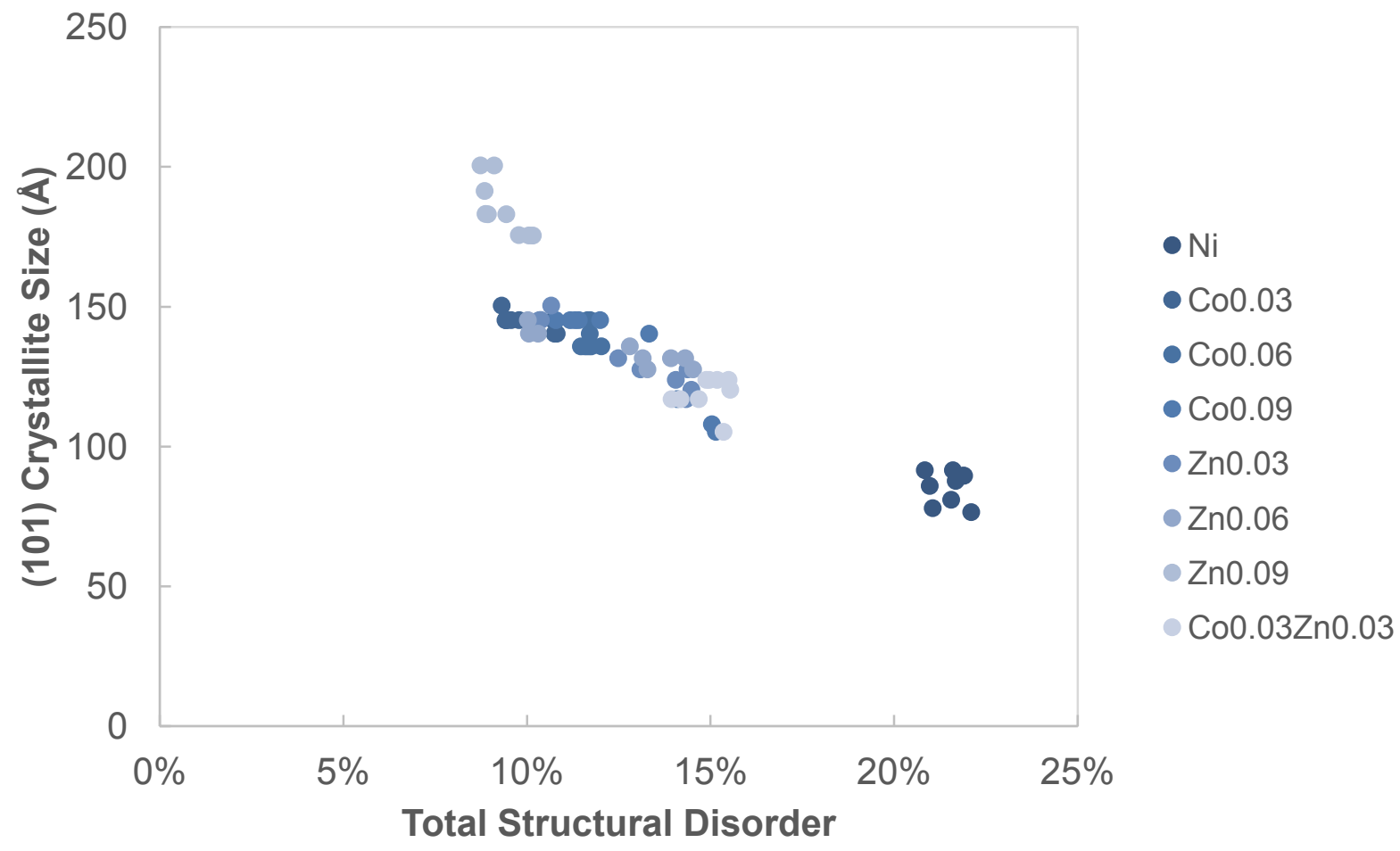

Fig. $4 a$ 


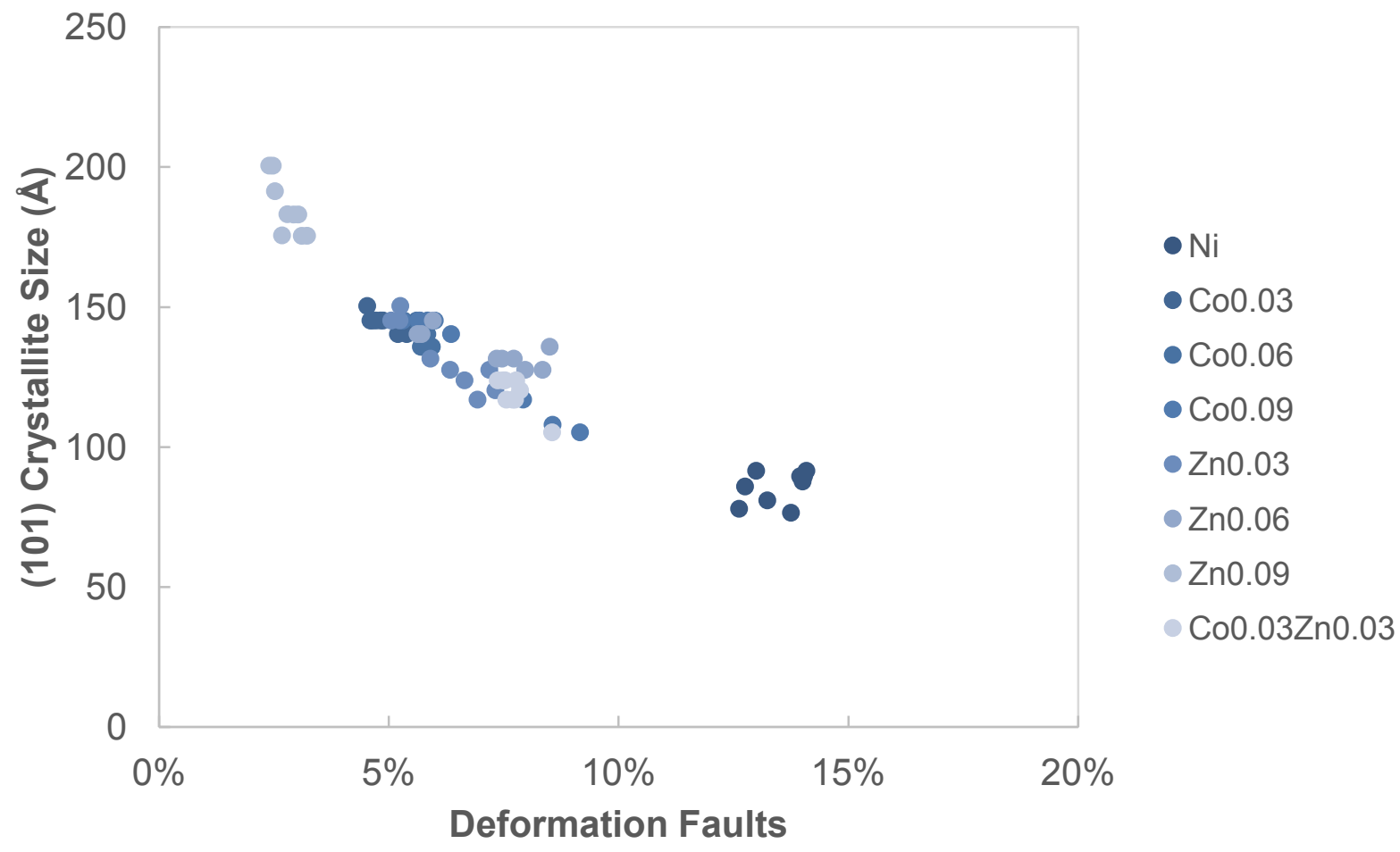

Fig. 4b 


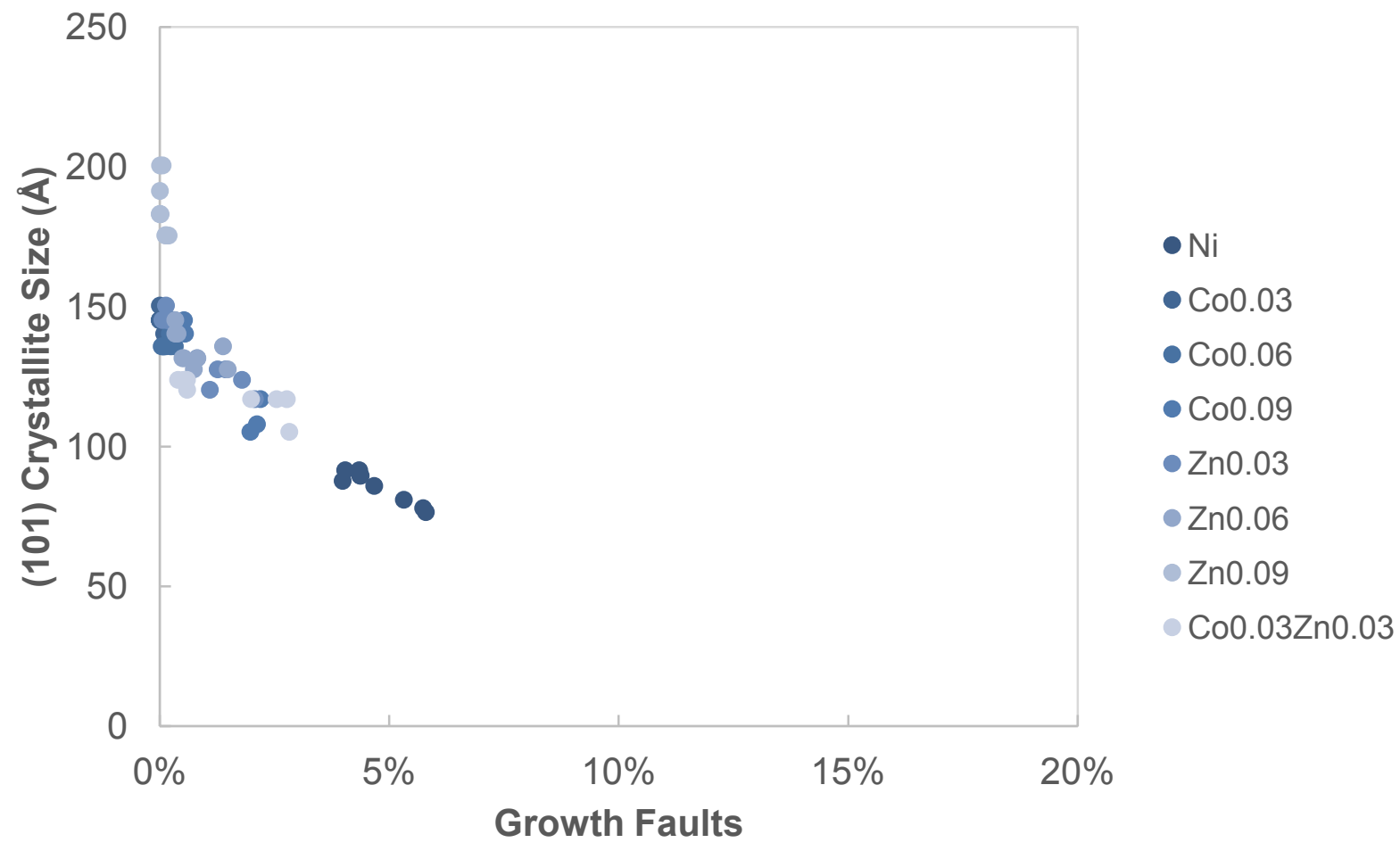

Fig. 4c 


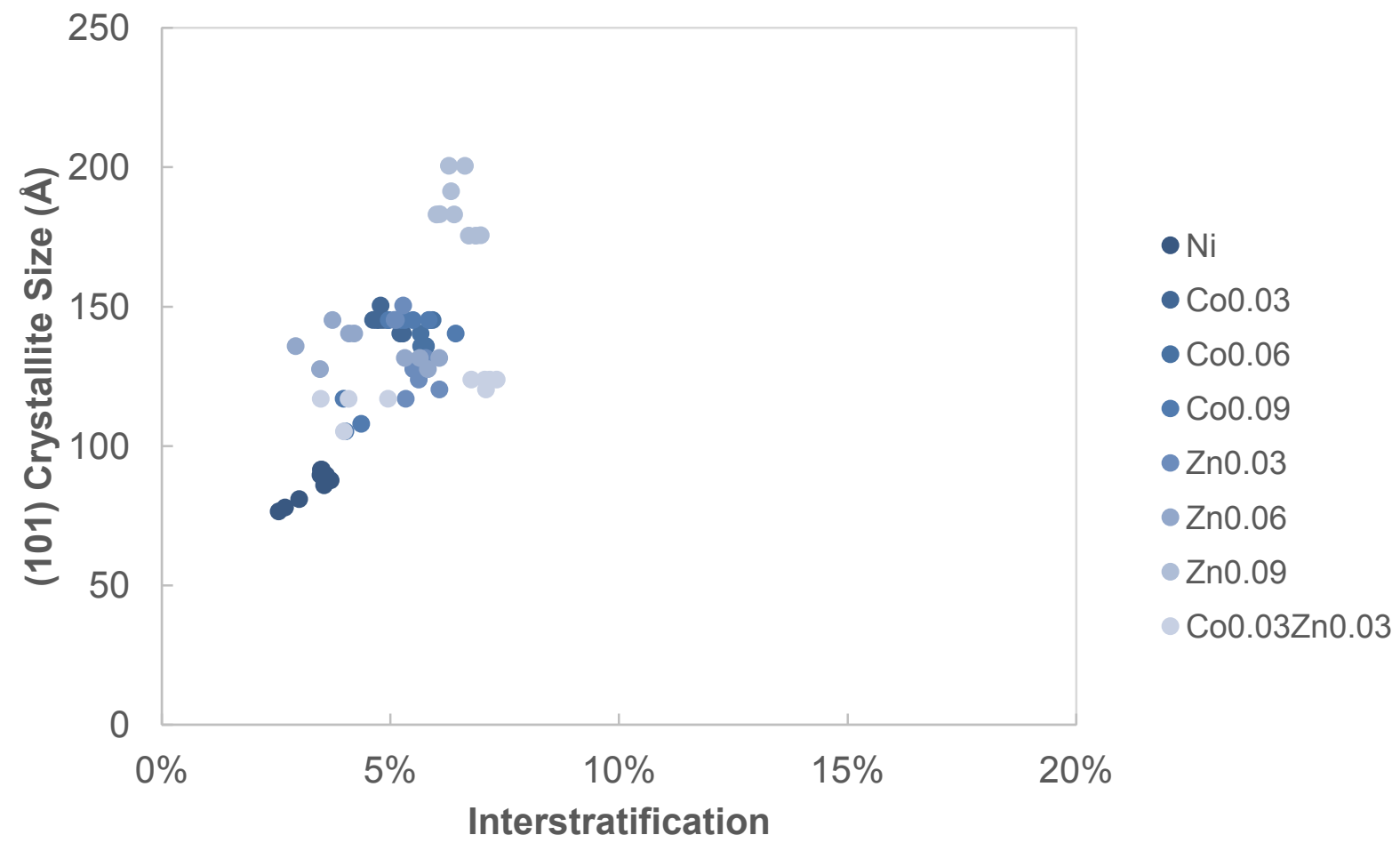

Fig. 4d 


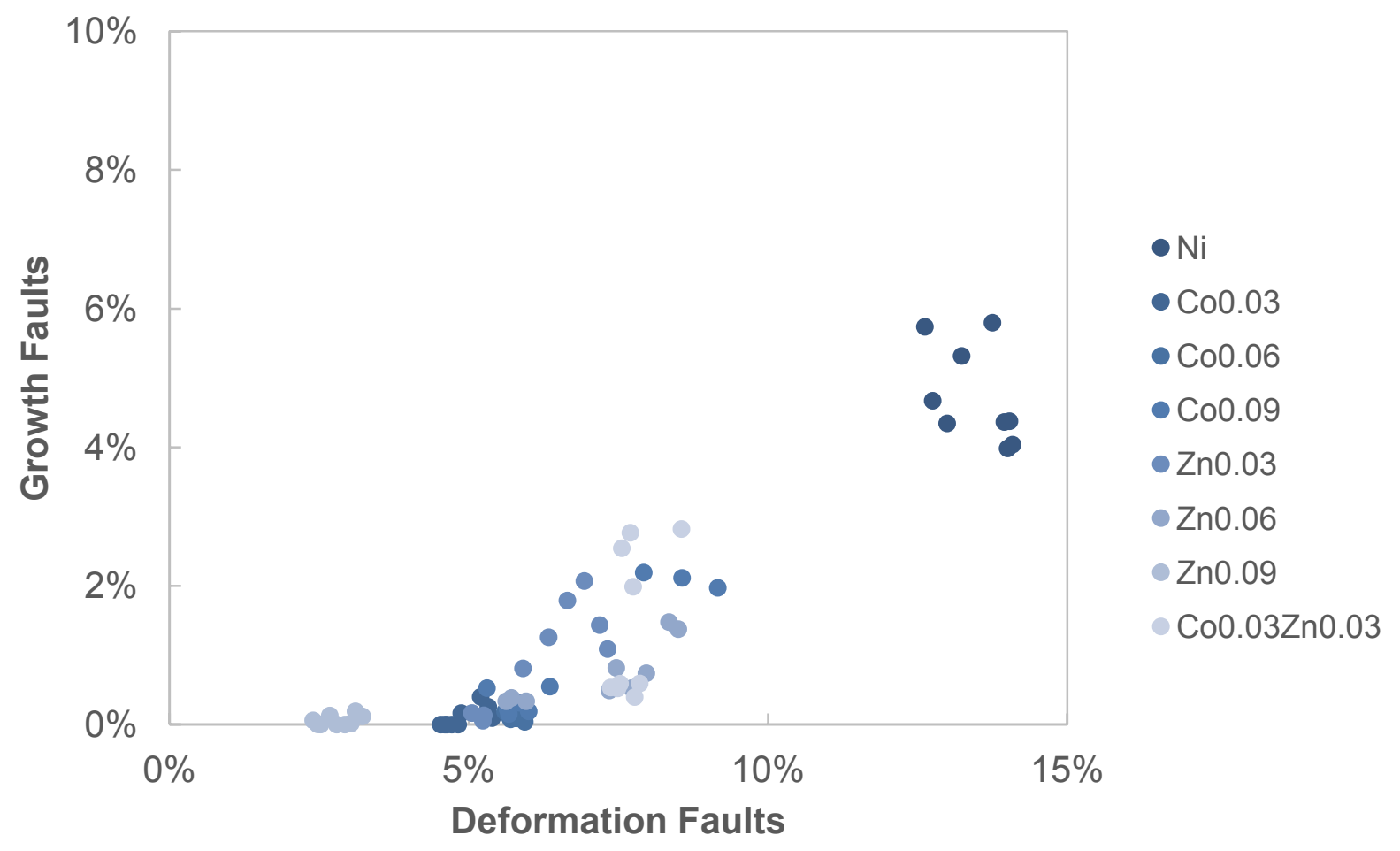

Fig. 5 


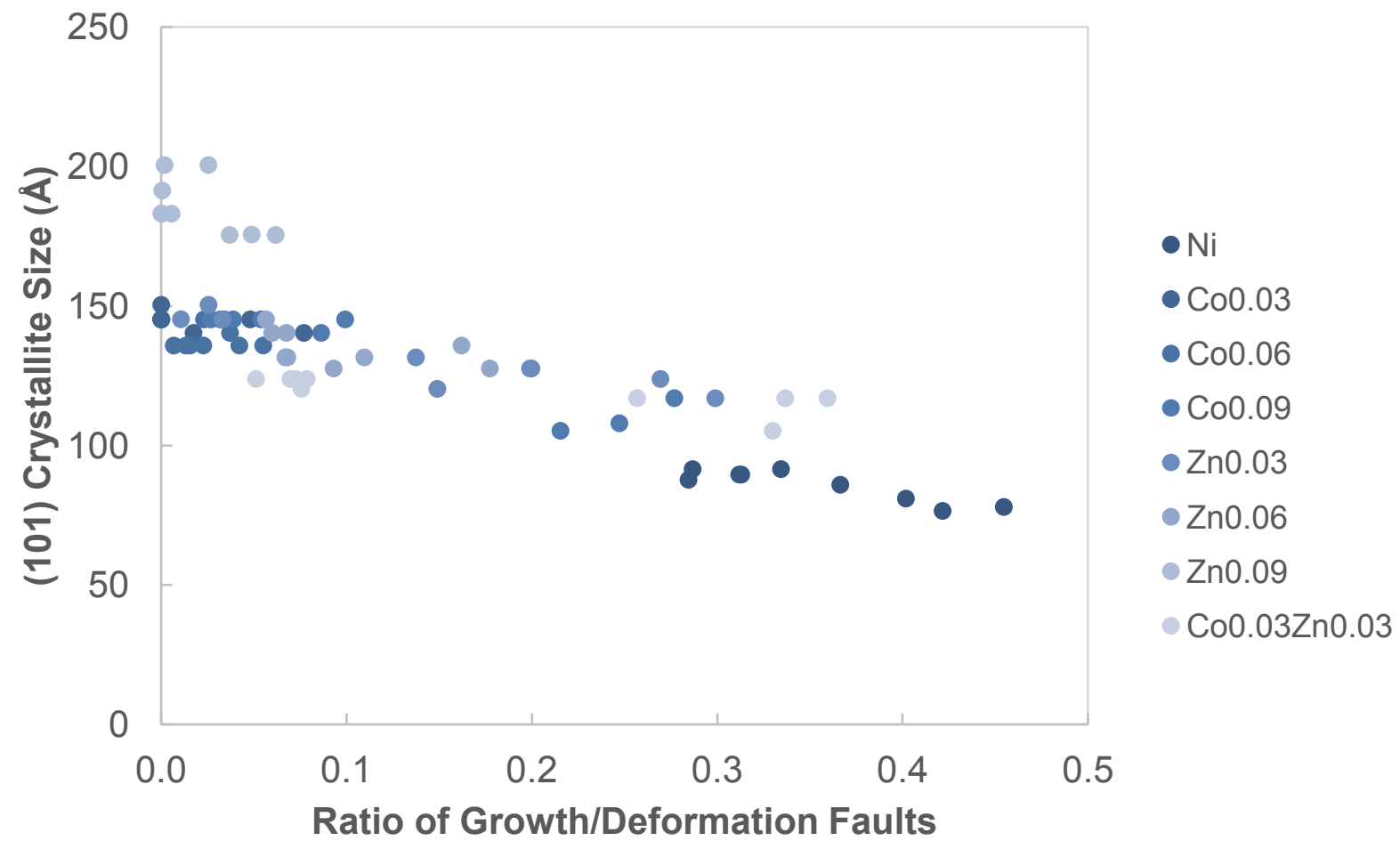

Fig. 6 


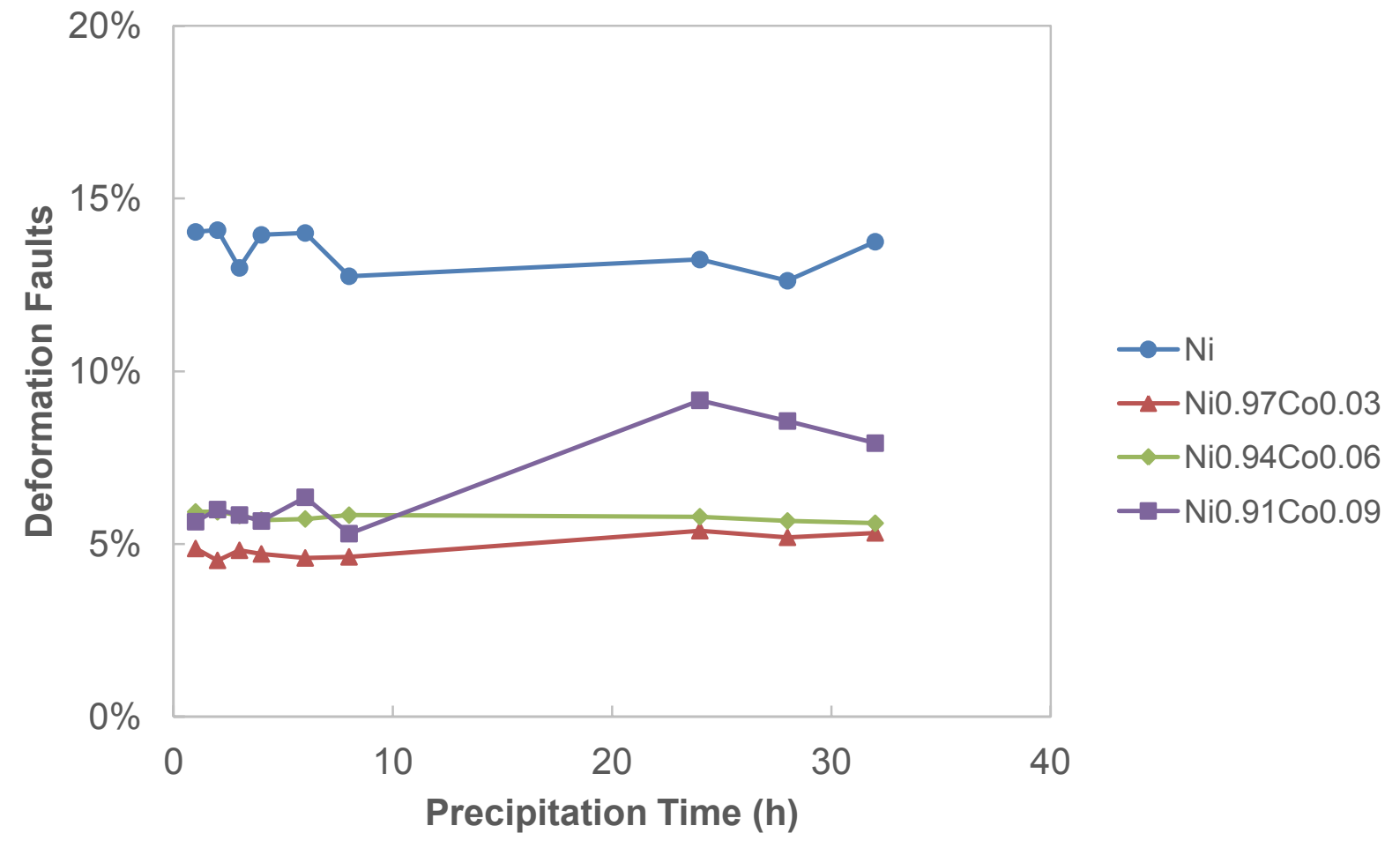

Fig. $7 a$ 


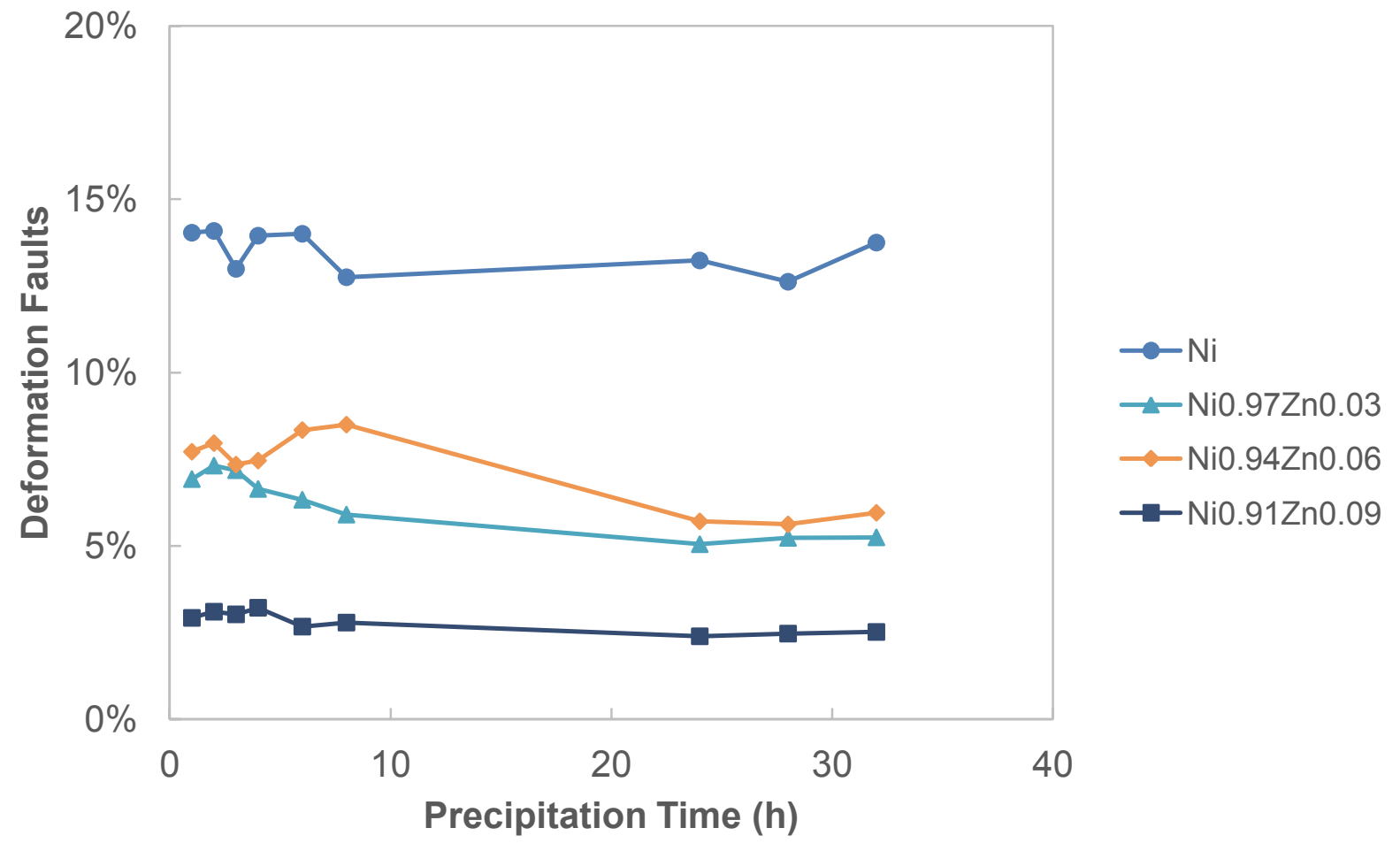

Fig. 7b 


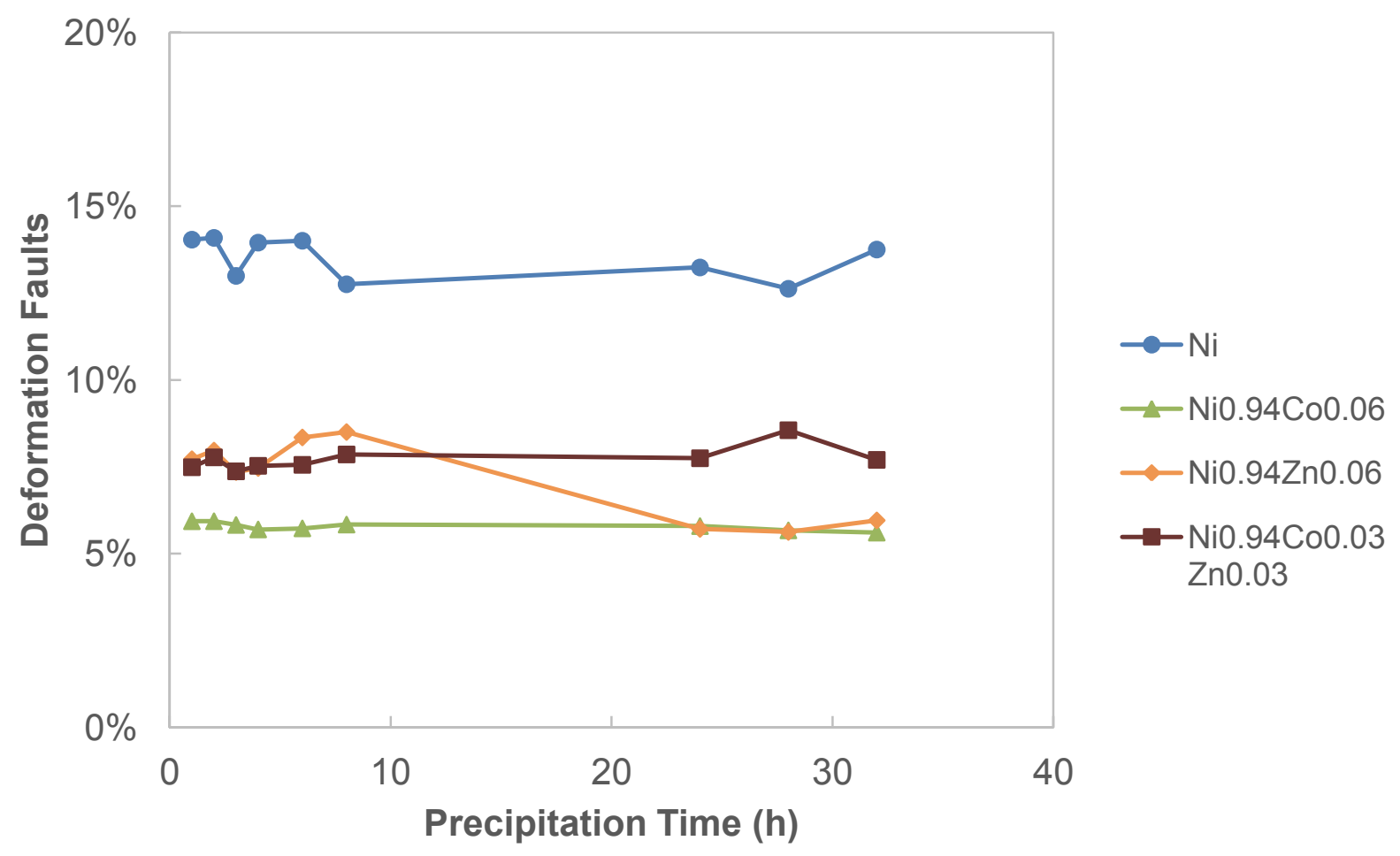

Fig. 7c 


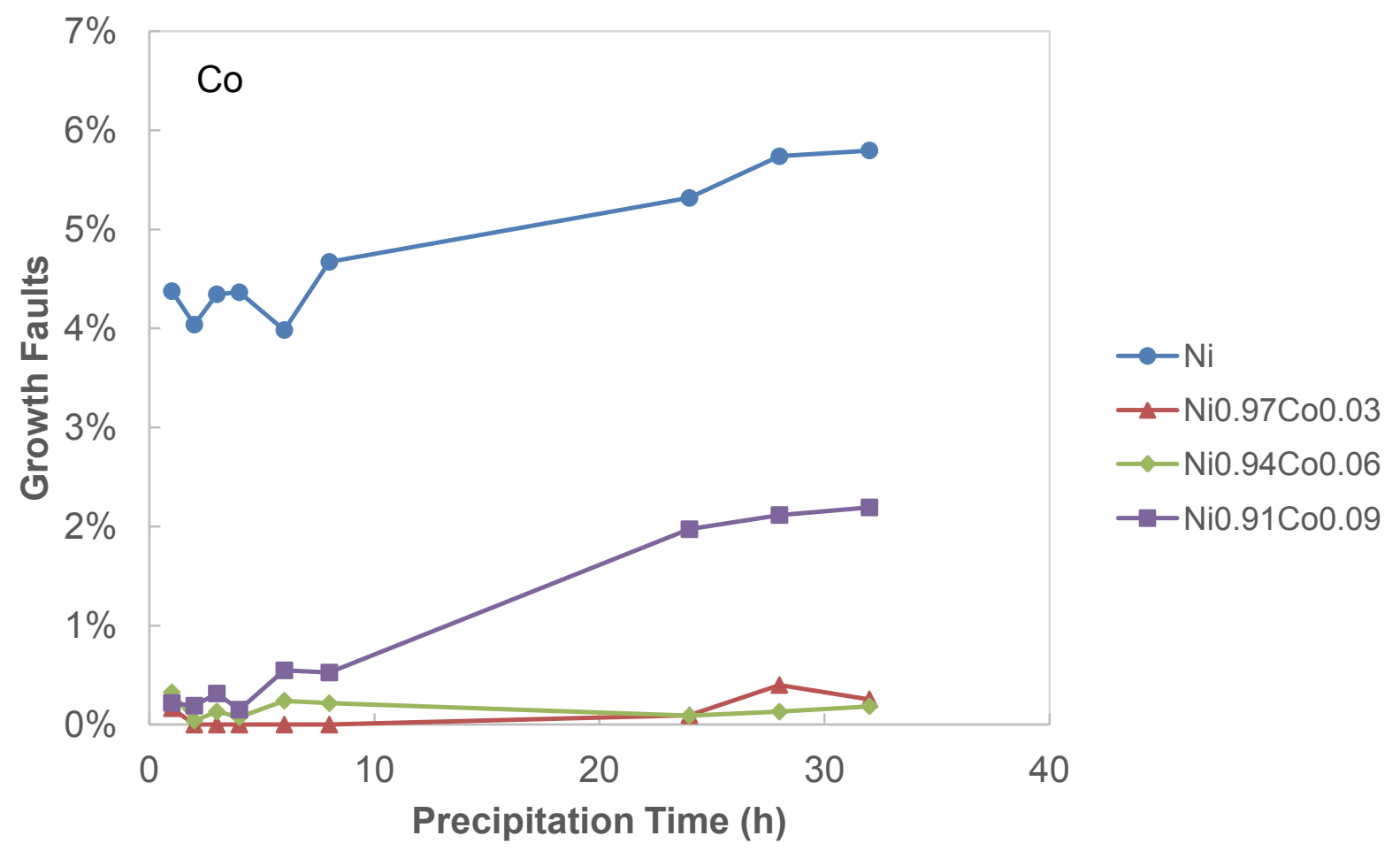

Fig. 8a 


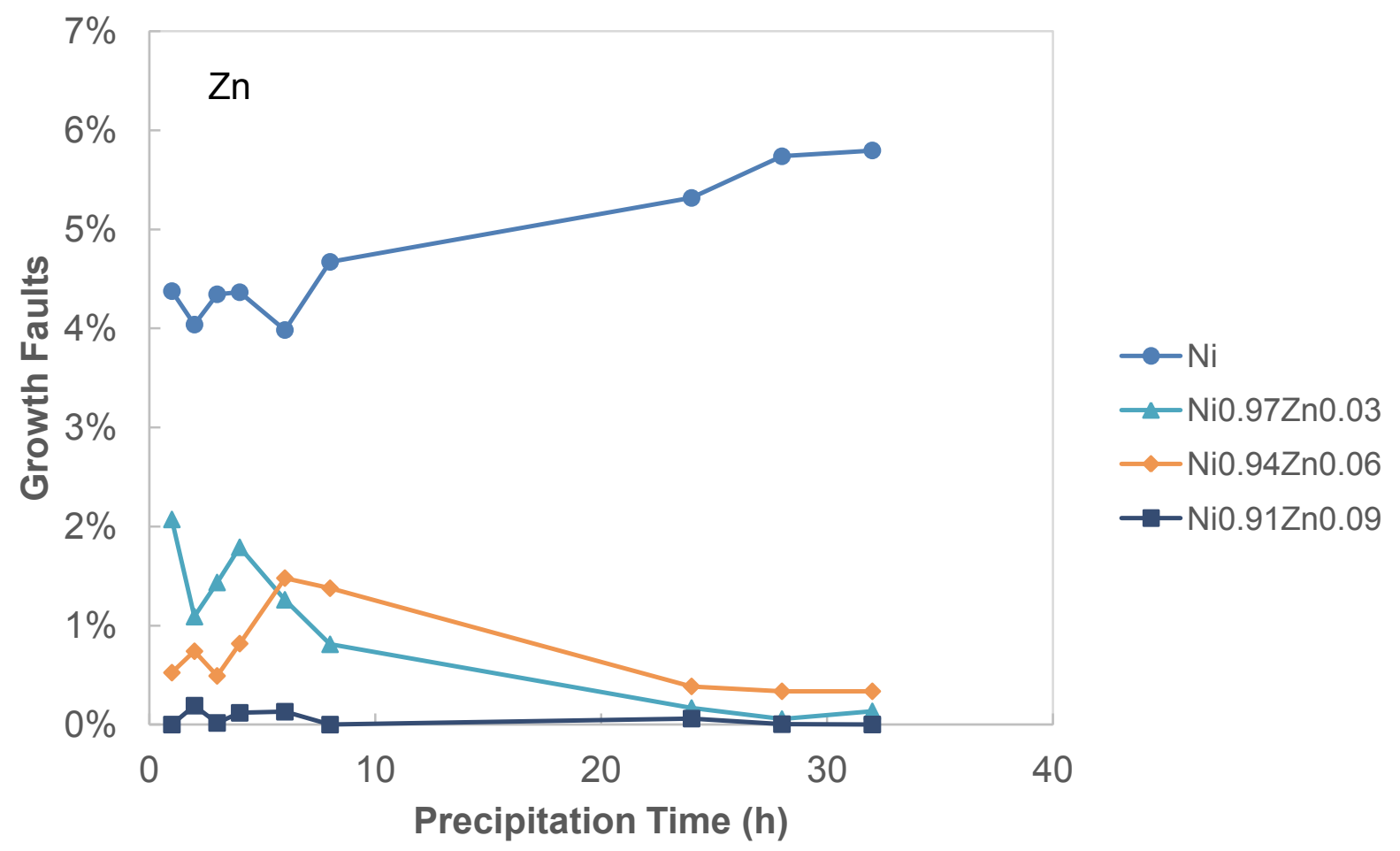

Fig. 8b 


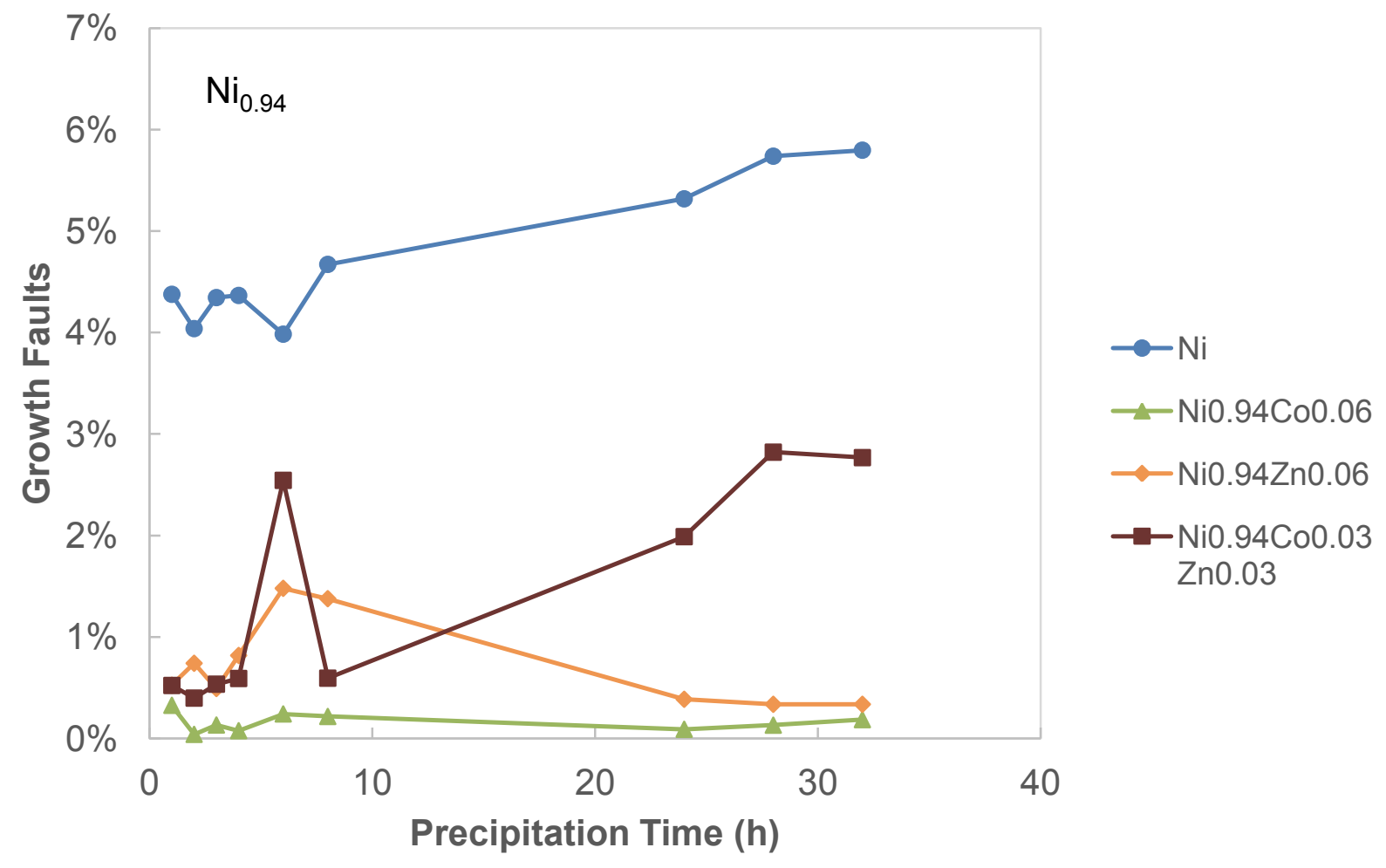

Fig. 8c 